\title{
O Financiamento Hipotecário da Cafeicultura no Vale do Paraíba Paulista (1865-87)*
}

\author{
Renato Leite Marcondes**
}

\begin{abstract}
Sumário: 1. Introdução; 2. O mercado hipotecário; 3. O crédito hipotecário no vale do Paraíba paulista; 4. Considerações finais.

Palavras-chave: mercado de capitais; economia cafeeira; história econômica paulista.

Código JEL: N26.

Este artigo analisa a importância do crédito hipotecário para o desenvolvimento da economia cafeeira no vale do Paraíba paulista, com base em três livros de hipotecas referentes às localidades de Guaratinguetá e Lorena. O artigo mostra a transformação das formas tradicionais de crédito (usurário) para a bancária a partir da lei hipotecária de 1864/65. Apesar das mudanças, o financiamento manteve-se restrito a uma pequena parcela da população e os mais afortunados conseguiam condições mais facilitadas.
\end{abstract}

This paper analyzes the importance of mortgage credit for the growth of the coffee economy in the Paraíba valley region, using as documentary sources three mortgage books from the localities of Guaratinguetá and Lorena. The paper shows how the traditional credit practices gave way to banking ones after the mortgage law of $1864 / 65$. Nevertheless, only a small percentage of the population benefited from the new form of financing, with the wealthier ones enjoying the best credit facilities.

\section{Introdução}

O crédito assumiu papel fundamental no desenvolvimento da economia cafeeira no vale do Paraíba paulista durante o século XIX. As formas de financiamento aos cafeicultores, demais agricultores e comerciantes passaram por mudanças significativas nesse período. A partir do Código Comercial de 1850 e da legislação hipotecária de 1864/65 a possibilidade de financiamento por meio de hipotecas e de instituições bancárias cresceu expressivamente. Anteriormente, o crédito concentrava-se nas mãos de capitalistas e comissários locais dos grandes centros comerciais, especialmente os da praça do Rio de Janeiro. O desenvolvimento do mercado de capitais após 1850 facilitou a

\footnotetext{
* Artigo recebido em maio 2000 e aprovado em jan. 2001.

** Professor da FEA/USP, campus Ribeirão Preto, e do Programa de Pós-Graduação em História Econômica da FCL/Unesp, campus Araraquara.
} 
realização de hipotecas e a aquisição de ações de companhias (ferroviárias, de transporte urbano, iluminação a gás etc.) e de apólices da dívida pública. ${ }^{1}$ Selecionamos para estudo o primeiro segmento deste mercado florescente.

Estas mudanças no mercado de crédito condicionam e são condicionadas pelas transformações da própria economia brasileira como um todo. O avanço do capitalismo em nosso país produziu uma alteração nas condições de financiamento, reduzindo o espaço do capital comercial e/ou usurário e incentivando o capital bancário. A modernização do mercado de capitais no país (bancos, sociedades acionárias etc.) encontrava-se limitada pelas imperfeições de mercado (elevados custos de transação e assimetria de informações, principalmente em regiões distantes dos grandes centros comerciais), as quais asseguravam a dominância do crédito pessoal. Este último, pautado por uma rede de relações de amizade, parentesco e dependência pessoal, facilitava a obtenção de informações sobre o devedor e o monitoramento sobre os pagamentos dos juros e amortizações. ${ }^{2}$ Como veremos adiante, quando ocorreu, a partir da década de 1870, o aumento da presença do capital bancário na região em questão, as condições para a manutenção do cultivo do café começavam a mostrar sinais de esgotamento, em especial na oferta de terras de qualidade e de mão-de-obra. Assim, se de um lado existiam melhores possibilidades de financiamento, de outro a produção cafeeira começava a apresentar seus limites de expansão na região.

Neste contexto, procuramos mostrar neste artigo o volume de crédito e as condições de financiamento hipotecário na região de Lorena e Guaratinguetá (na província de São Paulo) num momento áureo da cafeicultura no vale do Paraíba paulista. A documentação primária compulsada consistiu em três

\footnotetext{
${ }^{1}$ O fim do tráfico negreiro provocou um movimento de remanejamento de capitais alocados nesta atividade para outras. A realocação de recursos incrementou as transações monetárias e financeiras.

${ }^{2}$ A assimetria de informações era menor para o financiador local do que para o bancário da praça carioca ou paulistana. A presença no local e o conhecimento das pessoas permitiam aos credores da região uma melhor posição para a tomada da decisão de financiamento, sem a necessidade de intermediários. Assim, o empréstimo assumia um caráter eminentemente pessoal, reforçado por relações de parentesco e amizade. George D. Smith e Richard Sylla observaram uma situação próxima para os EUA antes da Guerra de Secessão: "Family connections and well-established personal alliances were crucial to conducting business in a world without high-speed transportation and telecommunications. Information was slow moving, fragmentary, and highly unreliable. (...) But until the development of large railroad systems after 1850, antebellum business, including commercial agricultural operations, remained small and local, and could normally meet their annual demands for working capital through the equity investments of wealthy individuals supplemented by rolling short-term credits via merchants or other unspecialized intermediaries" (Smith \& Sylla, 1993:9-10).
} 
livros de hipotecas, sendo dois para a primeira localidade e o outro para a segunda." Eles se destinavam "para a inscrição das hipotecas especiais, ou especializadas, e será escriturado na forma determinada no art. 26 do Regulamento Hipotecário de 26 de abril de 1865”. O período selecionado para estudo compreendeu os anos de 1865 a 1887, à exceção da localidade de Lorena, para a qual não houve registro de hipoteca em 1865.

Dividimos este artigo em três seções, além desta. A que se segue a esta introdução refere-se às mudanças no mercado hipotecário, que possibilitaram a expansão deste tipo de crédito a partir da década de 1860 . Na seção 3, analisamos, ao longo do período, o evolver das informações presentes na documentação (valor, taxa de juros, prazo e bens hipotecados), permitindo vislumbrar as condições de financiamento existentes na economia cafeeira. Por fim, procuramos entender os movimentos no mercado de crédito num contexto de transformação econômica por que passava a região naquele momento.

\section{O Mercado Hipotecário}

A ausência de um sistema bancário desenvolvido no período propiciava uma remuneração expressiva aos fornecedores do crédito para a economia cafeeira. Os poucos bancos existentes atuavam essencialmente por meio de sua carteira comercial de curto prazo e, dependendo da política econômica do momento, da capacidade de emissão. Na província de São Paulo, a situação do crédito mostrava-se ainda mais crítica, pois até 1870 havia apenas a Caixa Filial do Banco do Brasil e em 1880 existiam três bancos. Em 1889, encontravam-se em funcionamento no território paulista 10 bancos (Hanley, 1995:47-8). ${ }^{4}$ As elevadas taxas de juros implicaram constantes reclamações dos agricultores e habitantes de diversas localidades. Os cafeicultores pressionavam por formas de financiamento menos onerosas e a mais longo prazo. Flávio Saes observou para São Paulo em meados do século XIX: "o nível vigente da taxa de juros no intervalo de 12 a 18\% ao ano" (Saes, 1986:68). Em Lorena, Renato Marcondes verificou taxas ao redor de $20 \%$ para o período de

\footnotetext{
${ }^{3}$ Os livros de registro de hipotecas (os de número 2) encontram-se depositados no Cartório de Imóveis de Lorena e Guaratinguetá. As informações contidas nos livros são: data, nome, domicílio e profissão do credor e devedor, valor, prazo, taxa de juros e uma descrição sucinta do imóvel hipotecado. Anexos a esta última informação relacionavam-se os escravos dados em garantia.

${ }^{4}$ Devemos ter cuidado com estes dados, em virtude do grande relacionamento comercial e financeiro entre o vale do Paraíba paulista e o Rio de Janeiro.
} 
1830 a 1849 e de $16 \%$ para o momento de 1850 a 1872 nos créditos registrados nos inventários compulsados (Marcondes, 1998:230). ${ }^{5}$ A atuação de comissários e intermediários também provocava a elevação das taxas de juros para os tomadores finais. ${ }^{6}$

Neste sentido, Pandiá Calógeras revela a importância da nova legislação como uma tentativa de redução do custo dos empréstimos e alongamento do prazo de vencimento da dívida para os agricultores: "A lei de 24 de setembro de 1864 estabelecera as normas para os empréstimos sobre hipotecas; era possível, portanto, levar à carteira de emissões hipotecárias, inteiramente distinta da carteira comercial, esses títulos de liquidação remota, provindo, na realidade, e em sua grande maioria, de empréstimos concedidos aos agricultores, os quais, desse modo, entender-se-iam diretamente com o banqueiro sem o intermédio de terceiros nem o desembolso de corretagens especiais" (Calógeras, 1960:154). De outro lado, a reforma do Banco do Brasil implementada em 1866 também incentivava a transformação de parte da carteira comercial do banco em hipotecária e de penhor agrícola. As operações foram iniciadas em agosto de 1867 (Peláez \& Suzigan, 1981:115-6). ${ }^{7}$

\footnotetext{
${ }^{5}$ Pedro Carvalho de Mello definiu o panorama geral do mercado financeiro e de capitais nas décadas de 1870 e 1880 do seguinte modo: "as taxas de retorno estimadas para oportunidades de investimento de curto prazo, e com um risco relativamente bem pequeno, tais como depósitos à vista em bancos comerciais e aplicações em títulos governamentais, variavam entre 4\% e 6\%. As taxas obtidas na aplicação em títulos privados, como debêntures e letras comerciais, variavam de $7 \%$ a 9\%. Para os investimentos de longo prazo e com um risco relativamente alto, tais como aplicações em sociedades anônimas (e numa amostra que privilegiou aquelas de maior sucesso), as taxas de retorno variavam entre $9 \%$ e $11 \%$, ou mesmo alcançavam 12\%" (Mello, 1984:238). Devemos ressaltar que estas opções de investimento poderiam apresentar uma relação retorno/risco melhor do que a de financiar os cafeicultores do vale do Paraíba, especialmente ao final do terceiro quarto do século XIX (Schulz, 1996:227).

${ }^{6}$ Sebastião Ferreira Soares procurou explicar, no Relatório da comissão de inquérito sobre a crise financeira de 1864, os motivos das elevadas taxas de juros para os agricultores nos anos anteriores à lei hipotecária em função da presença de intermediários: "Em sua maior parte os dinheiros para suprimento dos fazendeiros são tomados pelos comissários aos seus banqueiros aos juros correntes, e sobre eles carregam mais $2 \%$ de garantia aos fazendeiros, de sorte que estes sempre pagam pelo menos mais $4 \%$ que o desconto estipulado pelo Banco do Brasil, porquanto não tendo, no cadastro do Banco do Brasil crédito aberto ao fazendeiros, as firmas destes não são aceitas naquele estabelecimento, pelo que só com as firmas dos comissários são descontados os seus títulos nos banqueiros, que assim se constituíram intermediários dos fazendeiros e do Banco regulador de crédito, e por isso mais 2\% carregam que o Banco pela sua garantia. Ora, sendo o desconto mais geral do Banco do Brasil na razão de 9 a $10 \%$ ao ano, segue-se que os fazendeiros mais favorecidos não obtêm dinheiro na praça com menores juros de 13 e 14\% ao ano, o que lhes é extremamente gravoso" (Ferreira, 1977:22).

${ }^{7}$ A conjuntura econômica da época favoreceu a expansão do crédito. Os gastos com a Guerra do Paraguai conduziram à ampliação da oferta de moeda em pouco mais de 100 mil contos de réis. Todavia, as demais fontes de financiamento foram mais importantes, sendo 265 mil contos com impostos e 171 mil com títulos (Peláez ES Suzigan, 1981:114).
} 
As taxas de juros das instituições que atuavam deste modo eram atraentes. O Banco do Brasil e o Banco de Crédito Real financiavam a uma taxa de juros de $6 \%$ ao ano com prazo de 20 anos no primeiro caso; $8 \%$ ao ano para prazos de cinco a 10 anos e $9 \%$ para 15 a 20 anos no segundo caso. Tais hipotecas atraíram os cafeicultores e modificaram as suas formas de financiamento. Joseph Earl Sweigart mostrou, ao estudar o financiamento da cafeicultura em Vassouras (situada no vale do Paraíba fluminense) durante a segunda metade do século XIX, a significativa alteração do sistema de crédito da economia cafeeira com a introdução das hipotecas: "A new era in agricultural finance in Brazil arrived with the conversion of the Banco do Brasil and the Banco Predial into mortgage institutions. The war with Paraguay had been won, and high coffee prices were propitius for the mortgate banks envisioned in the legislation of 1864 and 1865. (...) Companies would amass large amounts of capital to invest in plantations for long terms, under the improved credit conditions created by the clear registration of collateral: land and slaves. With risk diminished, planters would pay interest rates at or below the discount rate, thus eliminating the profit of the middleman" (Sweigart, 1980:140).

O crédito bancário revelou-se vantajoso para os agricultores em relação ao fornecido pelos comissários e capitalistas. Afonso de Escragnolle Taunay apontou um grande crescimento das hipotecas imobiliárias entre 1859 e 1864 . Os recursos emprestados concentraram-se nas três províncias cafeeiras (Rio de Janeiro, Minas Gerais e São Paulo), que mantinham cerca de 3/4 do total em 1859. Cinco anos mais tarde o volume dos compromissos chegou a dobrar, atingindo o valor de 40 mil contos de réis (Taunay, 1939:155, v. 4, t. II). ${ }^{8} \mathrm{~A}$ oferta de crédito hipotecário não se restringiu aos bancos, pois os capitalistas também passaram a fornecê-lo. Taunay, citando Van Delden Laerne, mostrou, para 1883, o alto grau de endividamento da cafeicultura no vale do Paraíba. Das mais de mil fazendas hipotecadas com o Banco do Brasil, Predial, e Crédito Real de São Paulo em quatro províncias, 409 foram de áreas de café do vale paulista e fluminense (39,8\% do total). Em Lorena, encontraram-se hipotecadas apenas três fazendas, que tinham pouco mais de 3 mil hectares, 791 mil pés de café e tão-somente 30 escravos. Os empréstimos para as três fazendas foram de 174 contos de réis, dos quais ainda restavam pagar 168

\footnotetext{
${ }^{8}$ O avanço do crédito hipotecário bancário em direção ao vale do Paraíba paulista iniciouse a partir do município do Rio de Janeiro, atingindo Bananal no final da década de 1860. Todavia, a presença mais expressiva de tais financiamentos só ocorreu a partir do final da década seguinte.
} 
contos (Taunay, 1939:383-93, v. 7, t. V). No caso de Guaratinguetá, existiam cinco fazendas com 794 mil pés de café e 176 escravos hipotecados. O total do financiamento chegou a 262 contos de réis (Taunay, 1939:391, v. 7, t. V). Como veremos adiante, este volume de recursos emprestados era muito reduzido em face do total dos financiamentos hipotecários efetuados nas duas localidades. De fato, a penetração do capital bancário revelava-se pequena em relação às esperanças dos cafeicultores. ${ }^{9}$

No referente ao crédito para a economia cafeeira, Pedro Carvalho de Mello enfatiza a imperfeição do mercado, os problemas de comunicações e transportes e as crises econômicas que explicariam as taxas de juros mais altas cobradas dos fazendeiros. Nas décadas de 1870 e 1880 a escassez de financiamento agrícola reduziu-se com a melhoria nos meios de transporte e comunicação. Além disto, a partir de 1867, a intervenção do governo por meio do Banco do Brasil, que passou a considerar pedidos de hipotecas, permitiu um financiamento a prazo mais longo e com taxas de juros mais reduzidas (fixadas em $6 \%$ e as amortizações em $5 \%$ anuais). O autor utiliza o trabalho de Jopeph Sweigart baseado em Vassouras para reafirmar tal quadro: “(...) os fazendeiros de café obtinham cerca de $40 \%$ de suas necessidades de capital das fontes locais. A maior parte desses emprestadores eram outros fazendeiros ou então comerciantes da cidade. Os empréstimos tinham por garantia hipotecas das propriedades rurais, o prazo era em geral de 2 a 4 anos e a taxa de juros oscilava entre 10\% e 12\%" (Mello, 1984:244).

Joseph Sweigart analisou 235 empréstimos garantidos por hipotecas às fazendas de café, registrados em Vassouras no período de 1873-84 no valor de 4.441 contos de réis. O valor médio destas transações chegou a quase 19 contos. Os credores denominados tradicionais eram os comissários de café (20,1\% dos empréstimos), fazendeiros e outros indivíduos da região (35,3\% das dívidas) e os comerciantes locais (5,6\% do total). Estes empréstimos deveriam ser amortizados em três anos em média e previam taxas de juros médias de 10,8\%. Os bancos hipotecários detinham 39,0\% dos créditos, sendo apenas o Banco do Brasil com 33,7\%.$^{10}$ Estas instituições emprestavam, em média,

\footnotetext{
${ }^{9}$ O primeiro financiamento hipotecário de bancos registrado nos documentos compulsados ocorreu primeiro em Guaratinguetá na passagem da década de 1860 para a subseqüente, em Lorena, ocorreu ao final da década de 1870. A chegada tardia do crédito bancário na última localidade deveu-se à forte presença de financiadores locais, como, por exemplo, a família Moreira Lima, que analisaremos mais adiante.

${ }^{10}$ Warren Dean, ao analisar o Oeste paulista nesta época, verificou uma situação distinta. Em Rio Claro, $80 \%$ dos valores emprestados registrados em 39 hipotecas e testamentos foram
} 
a taxas de juros de 6,9\% e amortizáveis em 13,1 anos (Sweigart, 1980:148). Assim, o crédito local ainda dominava o financiamento da cafeicultura, mas paulatinamente diminuía sua participação. ${ }^{11}$ Os cafeicultores pagavam as mais elevadas taxas de juros, em virtude do risco que representavam. O crédito local para os agricultores apresentava taxas similares aos dos investimentos de longo prazo e risco alto relatados por Mello, mas os prazos dos produtores agrícolas eram menores. ${ }^{12} \mathrm{~A}$ diferença nas taxas e nos prazos permitia às pessoas que recebiam os prêmios um processo de acumulação de riqueza muito superior ao dos demais indivíduos (Marcondes, 1998). Os emprestadores apropriavamse de parte do retorno esperado pelos tomadores em suas atividades, mas assumiam riscos elevados.

O avanço do crédito hipotecário por meio dos bancos ocorreu principalmente devido à atuação do Banco do Brasil. Em Vassouras, ele respondia por mais de 3/4 do financiamento bancário (Sweigart, 1980:147). Em 1880, o banco mantinha 29 mil contos em 676 hipotecas rurais, sendo 2/3 na área cafeeira fluminense. A deterioração das condições de reprodução da economia cafeeira no vale (a queda dos preços do café e os problemas de disponibilidade de mão-de-obra e de terras de qualidade) impunha limites à concessão de crédito. Em 1878, o Banco do Brasil recebeu 88\% das amortizações devidas, porém estes pagamentos só alcançaram $54 \%$ em 1884. Desta forma, o banco

de exportadores e comerciantes de Santos e Rio de Janeiro (Dean, 1977:48). Esta zona de fronteira mostrou uma carência de capitais elevada, favorecendo a expressiva participação dos recursos oriundos de outras regiões.

${ }^{11}$ O crescimento do capital bancário manteve a preponderância dos capitais nacionais na atividade creditícia. No caso de São Paulo, Anne Hanley observou: "An interesting characteristic of the bank sector during this period was its predominately domestic nature" (Hanley, 1995:51).

${ }^{12}$ Hebe Castro estudou as condições de financiamento existentes em Capivary (RJ) durante a segunda metade do século XIX. Como a região estudada por Castro não se encontra no vale do Paraíba, a cafeicultura não alcançou um desenvolvimento tão expressivo. O total das escrituras de penhor e hipoteca nos três cartórios locais chegou a 462 contos de réis. Este valor revelou-se muito inferior ao ocorrido nas transações das localidades valeparaibanas nessa época. A maior parcela deste valor foi negociada até 1870 (74,3\%). A partir desse ano o volume de crédito reduziu-se e a presença de relações financeiras com pessoas e firmas de fora do município aumentou, atingindo 53,7\% do total. Apesar disto, a autora verificou, no período anterior, uma certa independência das relações de crédito locais quanto às praças comerciais de fora da região: "O crédito fornecido por elementos de fora do município estudado representou apenas 26,2\% do montante negociado até 1870" (Castro, 1987:63). Nestes casos, as taxas de juros transacionadas variavam de $1 \%$ a $2 \%$ ao mês, parecidas com as de Lorena e Guaratinguetá. Apesar do crescimento do crédito de fora, houve uma busca de novos investimentos pela elite local: "Na década de 80, o montante declarado em dinheiro em espécie e principalmente títulos e apólices da dívida pública nos processos analisados somou mais de $50 \%$ do total de todas as fortunas inventariadas, representando em alguns casos mais de $80 \%$ do total" (Castro, 1987:66). 
deixou de realizar hipotecas rurais (Sweigart, 1980:189-90). Não apenas os múltiplos choques negativos que se abateram sobre a economia cafeeira explicam as razões desta medida, mas, como afirma Sweigart (1980:158): "Over the long run, the fundamental reason for the failure of mortgage banks lay not with slavery, but with the land, and the privileges accorded its owners". A existência de direitos de propriedade mal definidos dificultava a cobrança e a execução dos empréstimos, inviabilizando a continuidade da participação dos bancos no financiamento de hipotecas rurais na área cafeeira do vale do Paraíba.

\section{O Crédito Hipotecário no Vale do Paraíba Paulista}

Nos três livros consultados, os que cobrem o período 1865-87, constavam 347 hipotecas para Lorena e 567 para Guaratinguetá. ${ }^{13}$ O valor envolvido nestes negócios alcançou 3.804 e 5.927 contos, respectivamente (tabelas 1 e 2). A quantia média transacionada atingiu 10:962\$934 réis para a primeira localidade e 10:452\$912 réis para a segunda. Estes valores mostraram-se inferiores aos das hipotecas de Vassouras consideradas no estudo de Sweigart. Por outro lado, o volume total de recursos desta praça fluminense entre 1873 e 1884 também se revelou superior aos de Lorena e Guaratinguetá, tomados cada um per si, em igual período. Se admitirmos uma relação entre o volume de crédito e o patrimônio, isto apontaria para a existência, naquela região fluminense, de uma riqueza maior vis-à-vis a área paulista em questão.

No recenseamento de 1872 registraram-se 4.176 cativos na comarca de Lorena (que compreendia as paróquias de Lorena, Silveiras, Sapé e Embaú) e 4.352 escravos em Guaratinguetá. Já em Vassouras, havia 20.168 cativos (considerando as freguesias de Paty do Alferes, Sacra Família, Conceição e Mendes). Apesar de não haver informações precisas da área abrangida pelas três localidades, podemos afirmar que em termos absolutos, a riqueza existente em Vassouras era mais expressiva do que a observada nas duas localidades paulistas. Ademais, tal diferença mostrava-se maior em relação ao contingente cativo do que no tocante às hipotecas.

\footnotetext{
${ }^{13}$ Consideramos os casos de hipoteca com mais de um credor como transações distintas. Ocorreram cinco hipotecas nestas condições em Lorena e 13 em Guaratinguetá, das quais sete não apresentavam escravos entre as garantias. Nos demais 11 casos em que existiam cativos em garantia, os escravos foram divididos entre os credores de acordo com a sua participação no crédito.
} 
Tabela 1

Valores, taxas e prazos das hipotecas em Lorena (1866-87)

\begin{tabular}{|c|c|c|c|c|}
\hline Ano & Número & $\begin{array}{r}\text { Valores } \\
\text { (mil-réis) }\end{array}$ & $\begin{array}{c}\text { Taxa de juros } \\
\text { anual média }(\%)\end{array}$ & $\begin{array}{c}\text { Prazo médio } \\
\text { (anos) }\end{array}$ \\
\hline 1866 & 4 & 97:011 & 13,0 & 0,8 \\
\hline 1867 & 30 & $257: 216$ & 13,3 & 2,1 \\
\hline 1868 & 27 & $136: 877$ & 13,7 & 2,2 \\
\hline 1869 & 16 & $69: 218$ & 14,3 & 2,4 \\
\hline 1870 & 17 & 54:701 & 13,5 & 1,7 \\
\hline 1871 & 14 & $74: 348$ & 12,5 & 2,3 \\
\hline 1872 & 12 & $113: 100$ & 11,5 & 2,6 \\
\hline 1873 & 13 & $77: 407$ & 11,8 & 2,5 \\
\hline 1874 & 11 & $105: 244$ & 10,3 & 1,8 \\
\hline 1875 & 17 & $151: 828$ & 12,3 & 2,0 \\
\hline 1876 & 13 & $45: 930$ & 13,6 & 0,9 \\
\hline 1877 & 16 & $60: 655$ & 12,4 & 1,6 \\
\hline 1878 & 10 & $88: 420$ & 10,9 & 2,3 \\
\hline 1879 & 11 & $86: 245$ & 10,5 & 2,9 \\
\hline 1880 & 18 & 162:095 & 10,8 & 2,9 \\
\hline 1881 & 14 & 514:053 & 10,4 & 2,6 \\
\hline 1882 & 16 & $269: 366$ & 11,2 & 4,0 \\
\hline 1883 & 20 & 202:047 & 10,6 & 3,8 \\
\hline 1884 & 15 & $114: 494$ & 11,3 & 4,0 \\
\hline 1885 & 20 & $598: 257$ & 10,3 & 5,0 \\
\hline 1886 & 18 & $392: 153$ & 9,4 & 3,8 \\
\hline 1887 & 15 & $133: 475$ & 9,3 & 6,2 \\
\hline Total & 347 & $3.804: 138$ & 11,8 & 2,9 \\
\hline
\end{tabular}

Obs.: Nem todas as hipotecas apresentam as três informações. 
Tabela 2

Valores, taxas e prazos das hipotecas em Guaratinguetá $(1865-87)$

\begin{tabular}{|c|c|c|c|c|}
\hline Ano & Número & $\begin{array}{r}\text { Valores } \\
\text { (mil-réis) }\end{array}$ & $\begin{array}{c}\text { Taxa de juros } \\
\text { anual média }(\%)\end{array}$ & $\begin{array}{c}\text { Prazo médio } \\
\text { (anos) }\end{array}$ \\
\hline 1865 & 6 & 71.194 & 13,0 & 1,0 \\
\hline 1866 & 38 & 305.387 & 13,6 & 2,0 \\
\hline 1867 & 33 & 156.292 & 13,3 & 1,8 \\
\hline 1868 & 18 & 210.331 & 13,1 & 2,1 \\
\hline 1869 & 28 & 250.649 & 12,3 & 2,4 \\
\hline 1870 & 21 & 181.651 & 11,9 & 2,8 \\
\hline 1871 & 11 & 95.944 & 11,1 & 2,0 \\
\hline 1872 & 8 & 42.729 & 12,2 & 5,6 \\
\hline 1873 & 17 & 195.611 & 12,9 & 2,0 \\
\hline 1874 & 13 & 89.865 & 12,1 & 2,3 \\
\hline 1875 & 13 & 146.067 & 10,3 & 3,8 \\
\hline 1876 & 8 & 128.000 & 10,6 & 2,7 \\
\hline 1877 & 11 & 72.351 & 11,3 & 3,6 \\
\hline 1878 & 14 & 243.676 & 10,3 & 3,7 \\
\hline 1879 & 15 & 227.618 & 10,6 & 3,9 \\
\hline 1880 & 29 & 591.451 & 10,8 & 3,5 \\
\hline 1881 & 32 & 506.454 & 9,9 & 4,8 \\
\hline 1882 & 40 & 748.365 & 10,5 & 4,9 \\
\hline 1883 & 56 & 438.649 & 11,0 & 2,7 \\
\hline 1884 & 33 & 151.909 & 10,7 & 4,3 \\
\hline 1885 & 40 & 328.342 & 10,1 & 3,1 \\
\hline 1886 & 46 & 435.464 & 10,4 & 6,8 \\
\hline 1887 & 37 & 308.002 & 9,8 & 3,8 \\
\hline Total & 567 & $5.926: 801$ & 11,2 & 3,5 \\
\hline
\end{tabular}

Obs.: Nem todas as hipotecas apresentam as três informações. 
Ao analisarmos a distribuição dos valores hipotecados no vale do Paraíba paulista durante o período contemplado, notamos um ligeiro movimento de redução do volume de crédito transacionado na passagem da década de 1860 para a de 1870 (gráfico 1). ${ }^{14}$ Ao que tudo indica, quando se criou a possibilidade do registro de hipotecas houve a conversão de parte do estoque dos negócios realizados nos anos anteriores à lei para a forma hipotecária, em função da maior proteção ao credor neste último caso. Isto garantiu os volumes iniciais altos. Entretanto, as quantias hipotecadas reduziram-se ao final dos anos 1860. Talvez a Lei do Ventre Livre tenha ajudado a desorganizar o mercado hipotecário nos anos subseqüentes, pois, como os escravos garantiam também o empréstimo, os credores poderiam tornar-se, nesse momento, mais receosos quanto à concessão de novos financiamentos.

\section{Gráfico 1}

Valor total das hipotecas

(em contos de réis)

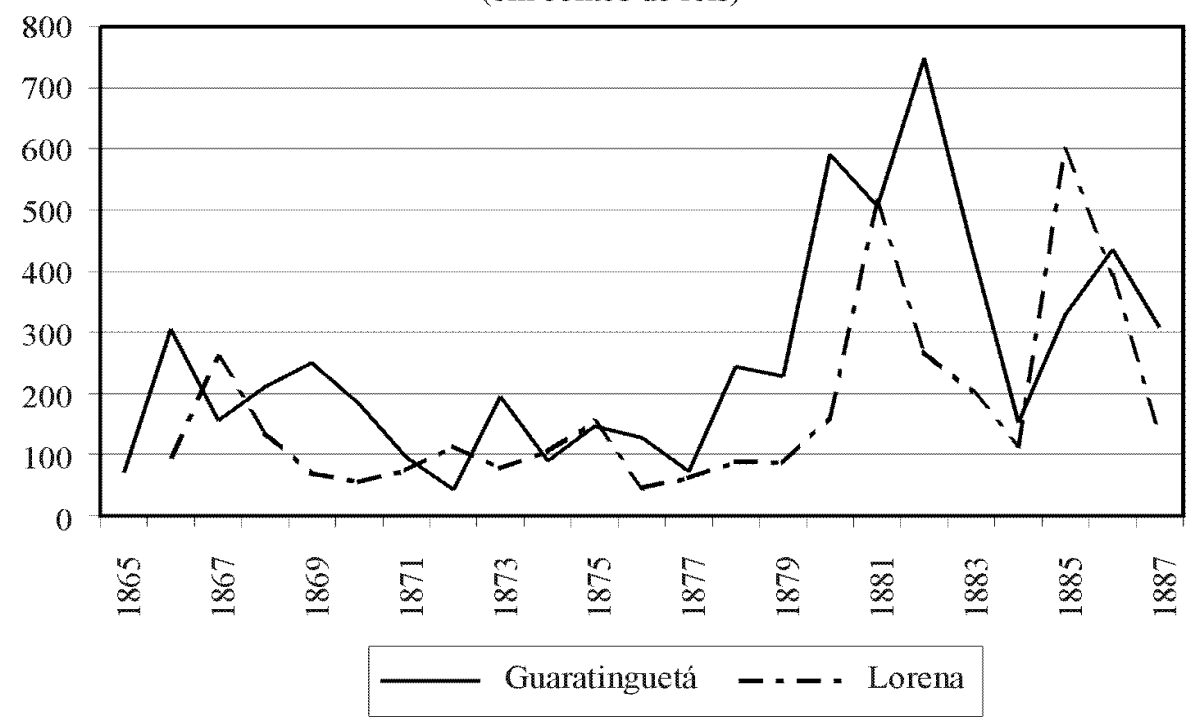

\footnotetext{
${ }^{14}$ Tais valores devem ser considerados à luz da variação dos preços. O índice construído por Luis Catão para o período 1870-87 mostra-se apropriado para esta tarefa. Segundo ele, o nível geral dos preços reduziu-se de 71,57 em 1870 para 57,36 em 1887 (Catão, 1992:530). O valor real das hipotecas efetuadas durante a década de 1870 alcançou 24,4\% das ocorridas no período 1870-87 em Lorena e 26,7\% em Guaratinguetá. No interregno 1880-85, notamos a realização de 58,0\% das quantias hipotecadas do período em questão referentes a Lorena e 56,7\% com relação a Guaratinguetá. Para 1886 e 1887, os percentuais seriam de 17,6\% e 16,5\%, respectivamente.
} 
A tabela 3 apresenta o preço médio dos escravos do sexo masculino em Guaratinguetá e Vassouras no período 1864-87. Podemos notar pelas informações apresentadas na tabela 3 uma tendência de retração dos preços dos escravos entre 1870 e 1873, possivelmente em virtude da Lei do Ventre Livre. ${ }^{15}$ Ademais, a crise econômica de meados dos anos 1870 pode também ter influenciado este resultado. ${ }^{16}$ A recuperação do volume de crédito negociado nas duas localidades só ocorreu a partir de 1877. A retomada dos recursos emprestados realizou-se de forma rápida e acentuada. No período 1880-85, as quantias transacionadas chegaram a 48,9\% do total para todo o período contemplado em Lorena e 46,7\% em Guaratinguetá. Na década de 1880, houve uma mudança da magnitude dos créditos concedidos nos financiamentos hipotecários da região, a qual atingiu, em alguns anos, mais de 500 contos de réis. A entrada dos bancos financiando os fazendeiros do vale explica esta transformação tão significativa. Entretanto, em 1886 e 1887, nas duas localidades houve uma retração no volume transacionado de financiamento, apontando as dificuldades crescentes vivenciadas pela economia cafeeira no vale do Paraíba a partir de meados da década de $1880 .{ }^{17}$

$\mathrm{O}$ crédito bancário somou-se às fontes tradicionais de financiamento da cafeicultura no vale do Paraíba. Os denominados "capitalistas" - residentes no vale - mantinham um forte controle da oferta de crédito. De fato, poucos indivíduos - e, muitas vezes, relacionados por vínculos de amizade e parentesco - detinham grande parcela dos recursos disponíveis para os empréstimos hipotecários. Entre estas pessoas, destaca-se a figura do português Joaquim José Moreira Lima (1807-79), morador em Lorena. Ele registrou 37 hipotecas

\footnotetext{
${ }^{15} \mathrm{O}$ coeficiente de correlação mostrou-se significativo apenas entre as variáveis preço dos cativos e taxa de juros em Guaratinguetá (-0,863). A oferta de crédito mais barato condicionou, e foi condicionada, o mercado de escravos. Entretanto, quando relacionamos o preço dos cativos com o valor das hipotecas a correlação não se revelou significativa. Posteriormente, a consolidação da percepção de que a lei não alterou, no curto prazo, as condições de produção permitiu o retorno dos fluxos de empréstimos e aumento dos preços dos escravos.

${ }^{16}$ O pânico instaurou-se no Rio de Janeiro ao final de 1874 com a contração do estoque de moeda. Segundo Peláez e Suzigan (1981:119), o estoque de M2 reduziu-se significativamente nos cinco trimestres subsequentes, o que levou, por exemplo, à falência do Banco Mauá EG Cia.

${ }^{17}$ Os movimentos do valor total das hipotecas nas duas cidades revelaram-se próximos. O coeficiente de correlação entre as quantias hipotecadas em Lorena e o Guaratinguetá atingiu 0,521 (tabela 4).
} 
Tabela 3

Preço médio dos escravos do sexo masculino em Guaratinguetá e Vassouras

$(1864-87)$

\begin{tabular}{|c|c|c|c|c|}
\hline \multirow[t]{2}{*}{ Ano } & \multicolumn{2}{|c|}{ Guaratinguetá } & \multicolumn{2}{|c|}{ Vassouras } \\
\hline & Número & preço médio (réis) & Número & preço médio (réis) \\
\hline 1865 & 5 & $1: 440 \$ 000$ & - & - \\
\hline 1866 & 7 & $1: 524 \$ 286$ & - & - \\
\hline 1867 & 4 & $1: 100 \$ 000$ & - & - \\
\hline 1868 & 1 & $1: 200 \$ 000$ & - & - \\
\hline 1869 & 5 & $1: 557 \$ 000$ & - & - \\
\hline 1870 & 5 & $1: 880 \$ 000$ & 57 & $1: 428 \$ 900$ \\
\hline 1871 & 3 & $1: 716 \$ 667$ & 1 & $1: 550 \$ 000$ \\
\hline 1872 & 1 & $1: 600 \$ 000$ & 2 & $1: 104 \$ 300$ \\
\hline 1873 & 9 & $1: 550 \$ 000$ & 146 & $1: 371 \$ 600$ \\
\hline 1874 & 8 & $1: 887 \$ 500$ & 8 & $1: 662 \$ 500$ \\
\hline 1875 & - & - & 30 & $1: 643 \$ 300$ \\
\hline 1876 & - & - & 7 & $1: 257 \$ 100$ \\
\hline 1877 & 5 & $2: 100 \$ 000$ & 8 & $1: 193 \$ 800$ \\
\hline 1878 & 17 & $2: 170 \$ 588$ & 9 & $1: 406 \$ 300$ \\
\hline 1879 & 11 & $2: 085 \$ 455$ & 11 & $1: 472 \$ 700$ \\
\hline 1880 & - & - & 3 & $1: 533 \$ 300$ \\
\hline 1881 & - & - & 3 & $1: 700 \$ 000$ \\
\hline 1882 & - & - & 28 & $1: 341 \$ 100$ \\
\hline 1883 & - & - & 17 & $723 \$ 500$ \\
\hline 1884 & - & - & 1 & $800 \$ 000$ \\
\hline 1885 & - & - & 22 & $715 \$ 900$ \\
\hline 1886 & - & - & 23 & $647 \$ 800$ \\
\hline 1887 & - & - & 44 & $255 \$ 700$ \\
\hline
\end{tabular}

Obs.: Agradecemos ao professor José Flávio Motta pelo fornecimento da série de homens de 15 a 39 anos para Guaratinguetá, baseada em escrituras de compra e venda de escravos. Com relação a Vassouras, os dados são de Pedro Carvalho de Mello e referem-se a homens de 20 a 29 anos. As suas fontes são inventários, anúncios de jornais e cartas de libertação de escravos (Mello, 1984:117). 
entre 1866 e 1878, totalizando 437 contos de réis. Esta quantia correspondia a cerca de $1 / 3$ do total dos empréstimos hipotecários da localidade. Em Guaratinguetá, ele possuía 14 hipotecas, totalizando 184 contos, que correspondiam a apenas 3,1\% do conjunto dos empréstimos. Quando ele faleceu, seus filhos continuaram a atuar no fornecimento do crédito na região. ${ }^{18}$

Nestas hipotecas registrou-se como garantia um grande número de escravos. Em Lorena, o total do contigente cativo anexado às hipotecas alcançou 1.625 cativos, sendo 533 entre 1880 e 1887 (32,8\% do total). Para Guaratinguetá, o número foi ainda maior, chegando a 2.331 pessoas, das quais 973 de 1880 a 1887 (41,7\% do contingente). A grande participação da massa escrava registrada nas hipotecas no total recenseado das localidades revela a importância desta fonte de recursos para a cafeicultura do vale do Paraíba. Calculamos um número médio de cativos relacionados nas hipotecas de 11,2 para Lorena e de 14,0 para Guaratinguetá. ${ }^{19}$

A parcela do valor das hipotecas do interregno 1880-87 em relação ao período todo superava a participação do número de escravos que garantiam os empréstimos de 1880 a 1887 com relação ao seu contingente total (186587). Todavia, apesar do crescente movimento abolicionista durante a década de 1880, os credores continuavam, em geral, a aceitar os escravos como garantia dos empréstimos, à exceção de alguns bancos que deixaram de fazê-lo nesse momento, mesmo existindo alternativas, pelo menos no plano formal, de penhor de safra e de maquinaria. Num cenário de fragilidade crescente da economia cafeeira no vale, é possível que faltassem estas opções para garantir os empréstimos, fazendo com que os credores continuassem anexando os cativos às hipotecas, apesar das perspectivas da Abolição. Da parte dos devedores, mostra-se vantajosa a manutenção desta prática de incluir um ativo de elevada incerteza quanto ao seu valor. Os cativos ainda representavam um importante

\footnotetext{
${ }^{18}$ Joaquim José Moreira Lima respondia sozinho por quase a metade dos financiamentos hipotecários realizados com capitais locais de Lorena. Este indivíduo mantinha também, nas localidades de Bananal e Areias, mais 34 hipotecas, somando 875 contos de réis. Seus empréstimos seguiam, grosso modo, o comportamento do valor total das hipotecas. Sua trajetória de vida é muito característica dos grandes "capitalistas" da época, pois se casa com uma filha do capitão-mor da vila na terceira década do século XIX e, atuando inicialmente como lojista de fazenda seca, pôde acumular um patrimônio extraordinário como usurário. A atividade prestamista não se restringia apenas às hipotecas. Ao falecer ele deixou cerca de $1 / 3$ de sua fortuna numa conta corrente de uma companhia carioca. Para uma análise específica da ação deste indivíduo, Marcondes 1998:240-6) ou, para uma versão mais aprofundada, Marcondes (2000).

${ }^{19}$ Não significa que a posse cativa fosse igual ao número relacionado na hipoteca, mas o devedor devia possuir pelo menos este número.
} 
ativo dos devedores. ${ }^{20}$ Robert Slenes (1986:110), ao analisar o vale do Paraíba fluminense, observou: "os fazendeiros do Vale continuavam expandindo seus cafezais e comprando escravos até o início da década de 1880". Segundo o autor, a estratégia dos cafeicultores do vale caracterizava-se, nesse momento, por aproveitar ao máximo a capacidade de produção existente, pois as condições de produção (mão-de-obra e produtividade da terra) deterioravam-se em termos absolutos e, principalmente, relativos. Este comportamento conduzia, no tocante ao crédito hipotecário, à obtenção de maiores financiamentos até uma restrição maior por parte dos credores, como a observada em meados da década de 1880 .

O valor da hipoteca mantinha uma correspondência com o contingente cativo registrado, pois este último representava uma parte importante da riqueza do proprietário. Deste modo, poderíamos esperar uma relação entre o número de escravos e o valor hipotecado. Em geral, observamos uma tendência de quanto maior o valor, mais escravos eram arrolados, especialmente para as propriedades rurais. Calculamos um coeficiente de correlação entre os dois ativos de 0,59 e 0,71 para as respectivas localidades, considerando apenas os informes em que se registraram a presença de escravos (145 casos para Lorena e 166 para Guaratinguetá). Este forte relacionamento decorria do predomínio de propriedades rurais entre as hipotecas com escravos, mais de $3 / 4$ do total. ${ }^{21}$ Ao realizarem uma transação de crédito agrícola, os contratantes procuravam manter, grosso modo, em geral, uma determinada proporção de terra e escravos. Todavia, um grande número de hipotecas não incluía, mesmo no período anterior à Lei do Ventre Livre, os cativos como garantia, sendo a propriedade de terra, cafezais e algumas benfeitorias os principais bens averbados na hipoteca.

\footnotetext{
${ }^{20}$ Os escravos representavam, às vésperas da Abolição, um contigente de trabalhadores muito importante na economia da região. Para grande parte dos escravistas, várias estratégias foram formuladas para conseguir trabalho de modo gracioso por mais alguns anos, mediante, por exemplo, cartas de liberdade sujeitas à prestação de serviço. Além disto, mantinham-se, pelo menos até 188\%, as transações de compra e venda de cativos na região. A última escritura deste tipo por nós localizada foi registrada em Cruzeiro (comarca de Lorena) no dia 23 de março de 1887, embora sujeita à condição de o escravo prestar serviço por prazo determinado (10 anos). A análise dos preços dos cativos mostra um crescimento ao longo da década de 1870 e uma redução significativa apenas durante a década de 1880 (tabela 3). Destarte, mesmo apresentando grandes incertezas, o ativo escravo permanecia nas negociações mercantis, especialmente nesta economia cafeeira.

${ }^{21}$ A diferença entre os coeficientes de correlação das duas localidades aponta para uma importância maior do crédito não-agrícola entre os financiamentos envolvendo cativos em Lorena. As atividades comerciais demandavam, proporcionalmente aos valores negociados, menos cativos do que as agrícolas.
} 
No gráfico 2, apresentamos as taxas de juros anuais médias para as duas localidades, as quais não revelavam diferenças significativas. O coeficiente de correlação entre as duas séries de taxa de juros chegava a 0,628 (tabela 4). As taxas de juros nos dois municípios apresentavam uma tendência de redução ao longo do período em estudo. No segundo lustro da década de 1860, observamos uma média de quase $14 \%$ para ambas áreas. Durante a década de 1870, houve uma redução das taxas, porém no momento da crise de 1874-76 verificamos, em Lorena, um aumento expressivo delas. Em Guaratinguetá não notamos tal comportamento, talvez em razão da diminuição do número de hipotecas registradas, especialmente as de valores menores. A chegada do capital bancário primeiro nesta última localidade ajuda a explicar este resultado. Após 1879, as taxas oscilaram entre 10\% e 11\%, chegando em 1887 com valores ao redor de $9,5 \% .{ }^{22}$ A partir do quadro oferecido pelos outros trabalhos realizados sobre este tema (vistos na seção anterior), verificamos taxas médias elevadas, equivalentes aos investimentos de longo prazo e risco expressivo.

Gráfico 2

Taxas de juros anuais médias

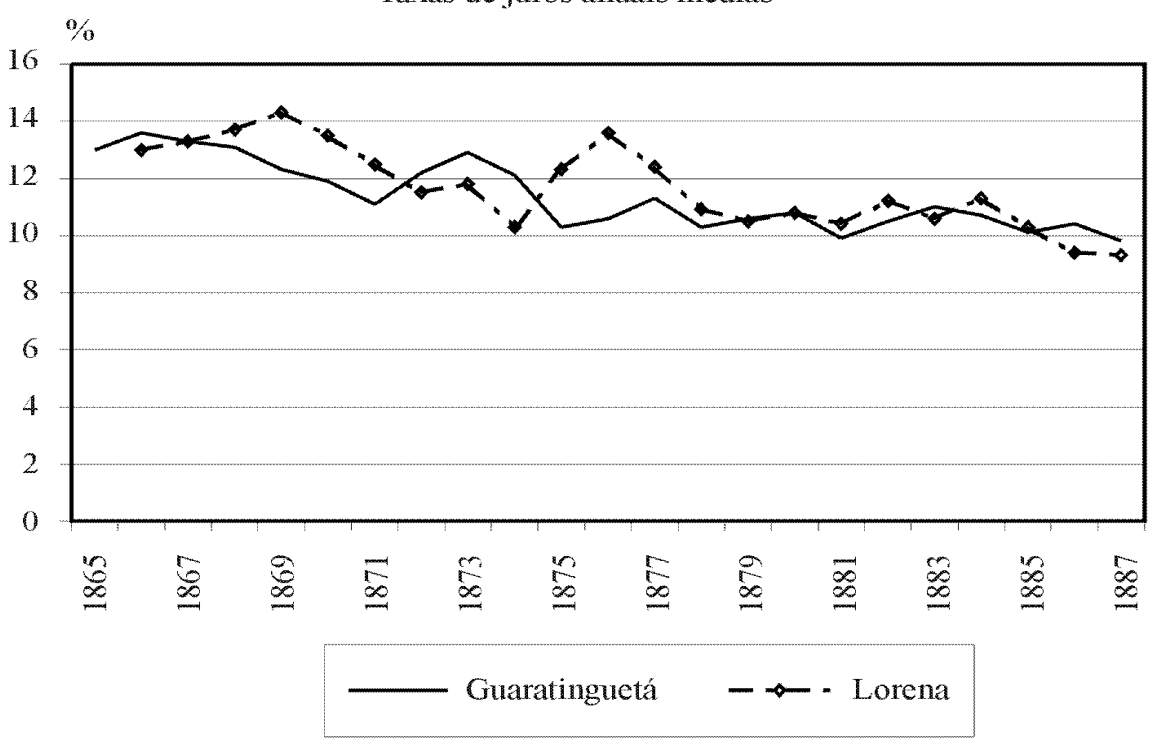

\footnotetext{
${ }^{22}$ Pedro Carvalho de Mello observou as taxas médias de juros cobradas em empréstimos pelos bancos comerciais de 1870 a 1882. Estas taxas passaram de uma média de pouco mais de $9 \%$ no início dos anos 1870 para menos de 8\% no começo da década seguinte (Mello, 1984:242).
} 
Tabela 4

Correlações entre as variáveis

$(1866-87)$

\begin{tabular}{lccccccc}
\hline $\begin{array}{l}\text { Localidade/ } \\
\text { Variável }\end{array}$ & \multicolumn{3}{c}{ Guaratinguetá } & & \multicolumn{3}{c}{ Lorena } \\
\cline { 2 - 3 } \cline { 7 - 8 } & Valor & Taxa de juros & Prazo & & Valor & Taxa de juros & Prazo \\
\hline Guaratinguetán & & & & & & & \\
Valor & 1 & $-0,404$ & 0,397 & & 0,521 & $-0,408$ & 0,431 \\
Taxa de juros & $-0,404$ & 1 & $-0,617$ & $-0,382$ & 0,628 & $-0,548$ \\
Prazo & 0,397 & $-0,617$ & 1 & & 0,376 & $-0,581$ & 0,402 \\
Lorena & & & & & & \\
Valor & 0,521 & $-0,382$ & 0,376 & 1 & $-0,471$ & 0,469 \\
Taxa de juros & $-0,408$ & 0,628 & $-0,581$ & $-0,471$ & 1 & $-0,690$ \\
Prazo & 0,431 & $-0,548$ & 0,402 & & 0,469 & $-0,690$ & 1 \\
\hline
\end{tabular}

Obs.: Para todas as correlações rejeitamos a hipótese de igualdade a zero dos coeficientes ao nível de significância de $10 \%$.

Os prazos médios dos empréstimos concedidos elevava-se no período em questão para ambas as localidades (gráfico 3). ${ }^{23}$ Até meados da década de 1870, o prazo médio não alcançava três anos, à exceção de 1872 para Guaratinguetá. Na década de 1880, o tempo médio dos créditos hipotecários superava os três anos, atingindo em alguns anos mais de cinco anos. No caso do período de vencimento da hipoteca, verificamos diferenças significativas entre as localidades estudas na década de $1870 .{ }^{24}$ Primeiro, elevou-se o prazo em Guaratinguetá e, posteriormente, em Lorena. Os diferenciais entre o tempo de empréstimo nessa época decorrem da presença mais intensa do crédito bancário naquela localidade em relação à esta. Entretanto, as duas cidades apresentaram uma retração do prazo de financiamento na passagem de 1875 para 1876, possivelmente em razão da conjuntura daquele momento.

\footnotetext{
${ }^{23}$ Em muito dos casos analisados não havia a informação do prazo e, em geral, era sem vencimento, ou seja a divida renovava-se perpetuamente. Estes casos ocorreram 87 vezes em Lorena (25,1\% do total) e 117 em Guaratinguetá (20,6\%). Em algumas destas hipotecas, o registro ocorria posteriormente ao vencimento da divida, possivelmente a fim de formalizar a divida e tentar assegurar seu recebimento.

${ }^{24}$ Embora o coeficiente de correlação do prazo fosse significativo (0,402), ele foi o menor entre os calculados para as variáveis valor e taxa de juros das duas localidades. Os movimentos das séries mostraram-se em idêntico sentido, porém havia uma diferença de patamar entre as duas localidades na década de 1870.
} 
Gráfico 3

Prazo médio das hipotecas

(em anos)

8
6
4
2
0

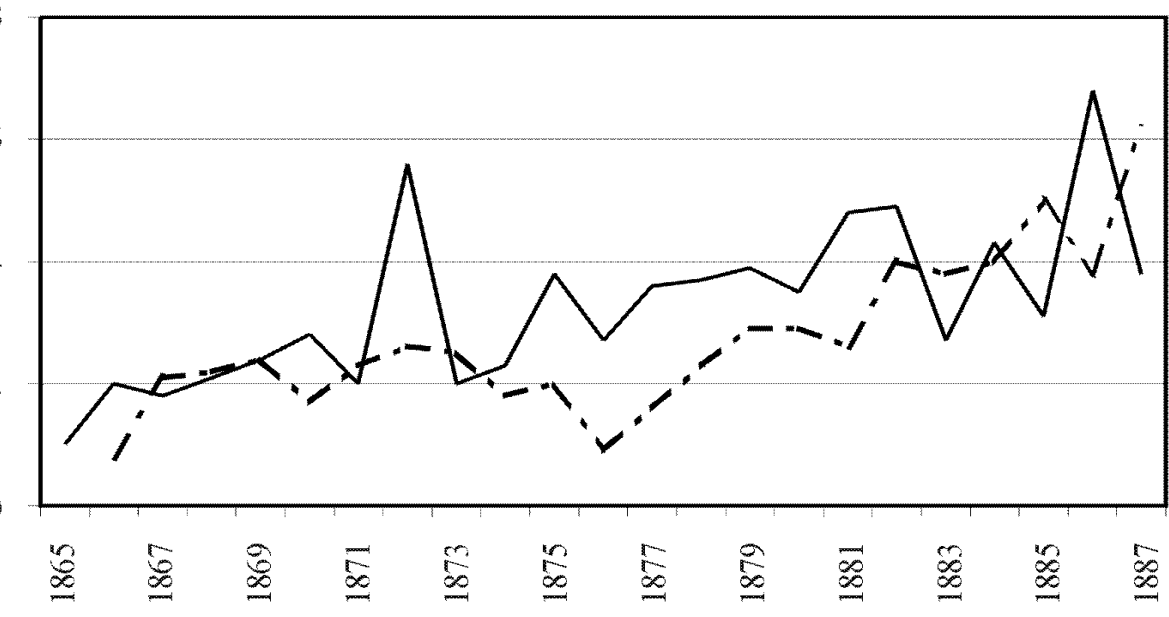

Guaratinguetá - - - Lorena

Por outro lado, observamos também uma diferença significativa no prazo dos empréstimos de acordo com o valor das hipotecas. Quanto maior a quantia transacionada mais longo era o prazo concedido ao devedor. Em Guaratinguetá, o prazo médio dos empréstimos de valor igual ou maior a 10 contos atingia 6,9 anos, enquanto os menores que este montante alcançavam apenas 2,1 anos. Em Lorena, verificamos os valores de 4,2 e 1,5 anos, respectivamente. Destarte, a análise do tempo de vencimento das hipotecas aponta para uma situação mais favorável aos devedores maiores em comparação aos menores; em geral, os grandes proprietários encontravam uma facilidade maior em conseguir o acesso ao capital bancário.

Esta distinção das condições de financiamento entre o porte dos empréstimos também revelava-se na análise da taxa de juros. Mantendo o corte de 10 contos, notamos uma maior taxa para as menores quantias (11,7\% para Guaratinguetá e 11,6\% no caso de Lorena). As hipotecas com valor igual ou superior a 10 contos apresentavam taxas de $10,0 \%$ e $9,5 \%$, respectivamente. ${ }^{25}$

\footnotetext{
${ }^{25}$ Quando realizamos uma regressão entre o valor da hipoteca com relação ao prazo e à taxa de juros transacionada, percebemos que ambas as variáveis são significativas, embora seu poder explicativo seja pequeno ( $R^{2}$ ajustado de 0,20 no caso de Lorena e 0,06 para Guaratinguetá). $O$ sinal das variáveis explicativas revela-se negativo para a taxa de juros e positivo para o
} 
O aumento do crédito bancário financiando os agricultores explica tal diferença. Os bancos emprestavam aos produtores agrícolas de maior porte a condições sem equivalência na praça local. Se havia a necessidade de tomar recursos, esta forma mostrava-se a melhor entre as alternativas disponíveis. Entretanto, o acesso a tal tipo de empréstimo restringir-se-ia a uma parte dos devedores, em geral os cafeicultores de dimensão expressiva, os quais mantinham uma rede de relacionamentos que alcançava os maiores centros econômicos (Rio de Janeiro e São Paulo). Os devedores nestas condições revelavam-se beneficiários de empréstimos a menores taxas de juros e maior volume de crédito.

A entrada em maior volume dos financiamentos bancários oriundos principalmente do Rio de Janeiro e de São Paulo não alterou significativamente a presença dos credores locais no volume concedido de crédito na região. Na gráfico 4 apresentamos a participação do crédito local no valor total das hipotecas. Embora oscilasse muito a parcela dos financiadores locais no conjunto dos empréstimos, ela chegava a 58,6\% em Lorena e a 50,2\% em Guaratinguetá no período 1865-87. Novamente, notamos na primeira localidade a existência de uma elite mercantil mais atuante do que na última, o que retardou a entrada dos bancos. Na década de 1880, esta participação era um pouco menor, $54,6 \%$ e $48,8 \%$, respectivamente. Enquanto os credores locais realizavam três vezes mais hipotecas do que os de fora da localidade para as quantias menores do que 10 contos, os primeiros faziam um número quase igual de empréstimos com relação aos segundos para valores acima de 10 contos em Lorena durante 1880-87. No caso de Guaratinguetá, para idêntico momento, os primeiros superavam os segundos na faixa de valor hipotecado menor do que 10 contos em cerca de seis vezes, e na faixa acima de 10 contos havia a quase igualdade. Com a entrada dos bancos do Rio de Janeiro e de São Paulo, os credores locais concentraram seus créditos para os devedores das menores quantias e, como observado por Marcondes (1998, cap. 6), procuram investir seus recursos fora da localidade, pois já vislumbravam as dificuldades crescentes da economia cafeeira. 
Gráfico 4

Participação do crédito local no valor total das hipotecas

(em percentagem)

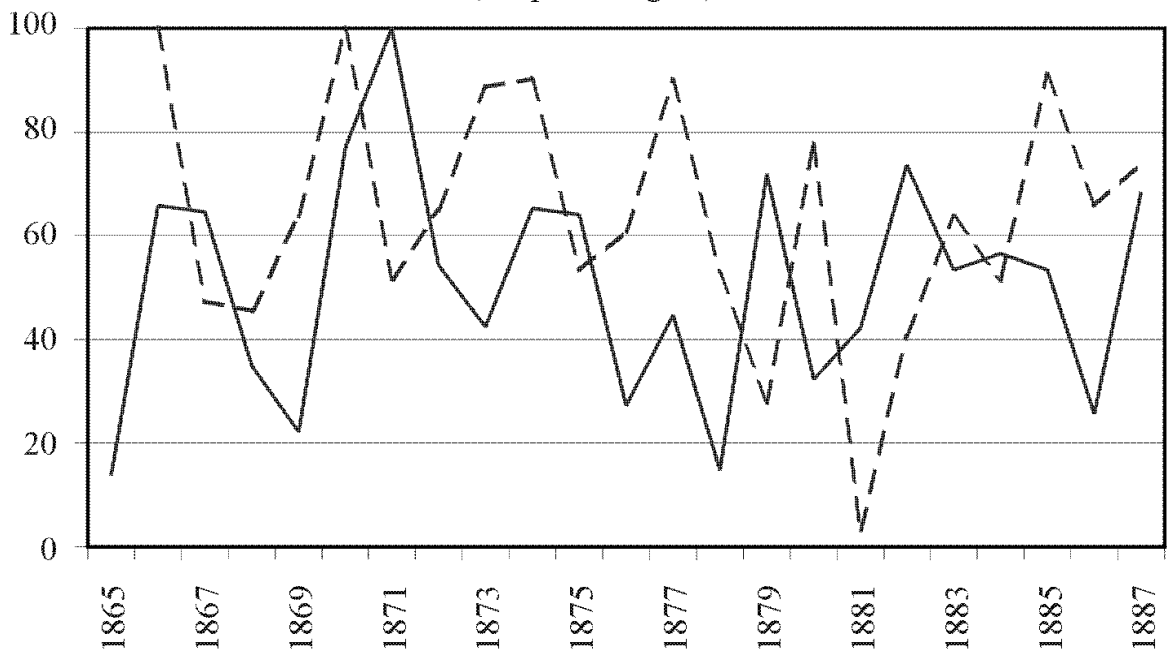

\section{Guaratinguetá $\quad-m-$ - Lorena}

\section{Considerações Finais}

O rápido avanço da cafeicultura pelo vale do Paraíba contou, desde o seu início, com o fornecimento de crédito pela elite mercantil regional. As condições destes financiamentos revelaram-se extremamente desfavoráveis para os devedores, com elevadas taxas de juros e prazos curtos. ${ }^{26}$ A ausência de um sistema bancário desenvolvido na região possibilitava a cobrança de taxas de juros acima das utilizadas pelos bancos comerciais nas praças do Rio de Janeiro e de São Paulo. Os rentistas e alguns fazendeiros dominavam o crédito no vale. Os tomadores destes recursos só conseguiam honrar estes financiamentos graças à rentabilidade elevada da cafeicultura naquele momento.

A existência desta forma de crédito não impediu que o financiamento fosse uma alternativa importante para a expansão cafeeira. O desenvolvimento do

\footnotetext{
${ }^{26}$ Sobre a acumulação de riqueza dos indivíduos que viveram nessa sociedade durante o século XIX, ver Marcondes (1998).
} 
mercado de capitais permitiu, especialmente após a lei hipotecária de 1864 , a entrada dos bancos no fornecimento de recursos para a economia cafeeira. Entretanto, mesmo com a entrada das instituições bancárias na década de 1870, o crédito continuou restrito, em função dos problemas de risco e assimetria de informações. De fato, o financiamento encontrava-se longe da situação ideal de provimento de crédito, ao ser intermediário entre os detentores de poupança e os investidores. Este cenário mantém-se apenas no plano teórico distante do contexto econômico e social da época. ${ }^{27}$

Em nosso estudo, o crescimento do volume de empréstimos na região deveu-se à entrada dos capitais de origem bancária. Todavia, a maior oferta de crédito beneficiou tão-somente os agricultores de maior porte, com maiores quantias emprestadas a menores taxas de juros e a prazos mais longos. Tais empréstimos não alcançaram grande parcela dos que necessitavam de recursos. A diminuição da rentabilidade cafeeira, aliada às dificuldades crescentes com relação à mão-de-obra cativa, impunha aos que não conseguiam financiamentos nessas condições um ônus demasiadamente grande para os devedores, o que muitas vezes os conduziram a deixar de realizar os pagamentos dos juros e amortizações. Entre 1865 e 1887, apesar da melhora das condições médias de empréstimos, apenas uma pequena parcela dos devedores se beneficiou delas, os quais tinham condições de acessar o mercado de crédito dos grandes centros. Ao final da década de 1880, a deterioração da situação da economia cafeeira na região mostrava-se mais evidente. Assim, não apenas os menos afortunados revelavam-se premidos pela impossibilidade de honrar seus compromissos financeiros, chegando a perder suas propriedades, mas também os que foram favorecidos pelos empréstimos dos bancos também apresentavam problemas para manter-se em dia com seus pagamentos.

Apesar da redução das taxas de juros e o alongamento dos prazos dos financiamentos dos mais ricos, a piora das condições de produção do café

\footnotetext{
${ }^{27}$ Neste sentido, aproximamos da evidência encontrada por Naomi R. Lamoreaux para a Nova Inglaterra (EUA) no início do século XIX: "For years scholars have seen the persistence of traditional social institutions, and especially kinship-oriented businesses, as major impediments to economic development. This view is currently changing, however. Indeed, some students of third-world economies point out that the diversified operations of kinship groups may actually facilitate development by compensating for the high levels of risk and the lack of organized markets that characterize preindustrial societies. At the same time my own work on the New England economy suggests that kinship groups can fulfill this role only with the help of their affiliated banks. Banks not only enable theses groups to raise capital from outside their networks, they provide them with an institutional foundation suitable to the special demands and time horizons of industrial enterprise" (Lamoreaux, 1986:666).
} 
no vale relativamente às existentes em outras regiões impunha dificuldades à manutenção do crédito. O vislumbre da decadência da região na passagem da década de 1870 para a de 1880 não inviabilizou o aumento dos volumes de recursos registrados nas hipotecas, em virtude da estratégia dos cafeicultores de aproveitar ao máximo a capacidade produtiva existente e, possivelmente, da retração das outras formas de empréstimos disponíveis (não-hipotecárias). A redução do crédito por meio de hipotecas (1886 e 1887) ocorreu apenas quando a crise da região já se manifestava mais pronunciadamente (Slenes, 1986).

Num momento de crescente vicissitude da economia cafeeira ao longo da década de 1880, o aumento da concorrência e da possibilidade de aplicar os recursos disponíveis fora da região provocou, primeiro, a retração da atuação dos credores locais no suprimento do crédito. O desenvolvimento do mercado financeiro e do sistema de transportes facilitou o movimento de pessoas e capitais pelo território. Destarte, os detentores de bens procuraram alocar parcela crescente de sua riqueza em outros ativos, como, por exemplo, títulos públicos (especialmente na época da Guerra do Paraguai) e outros valores mobiliários (apólices, depósitos, ações etc.), localizados nos dois principais centros mercantis (São Paulo e Rio de Janeiro). ${ }^{28}$ De outro lado, uma parte dos próprios cafeicultores que conseguiram amealhar um certo patrimônio procurou acompanhar o roteiro do café em direção ao Oeste paulista. A migração de recursos para outras regiões acelerou a retração do crédito no vale do Paraíba paulista a partir de meados da década de 1880.

\section{Referências Bibliográficas}

Calógeras, João Pandiá. Política monetária do Brasil. São Paulo, Companhia Editora Nacional, 1960.

Castro, Hebe Maria da Costa Mattos Gomes de. Ao sul da história: lavradores pobres na crise do trabalho escravo. São Paulo, Brasiliense, 1987.

\footnotetext{
${ }^{28}$ A realocação da riqueza entre os diversos ativos ocorreu, em São Paulo, ao longo da segunda metade do século XIX: "Os movimentos por nós detectados - o declínio dos escravos vis-à-vis o aumento dos imóveis, o aparecimento de formas avançadas de riqueza, especificamente as ações e secundariamente as contas e letras bancárias, o declínio dos animais e a presença constante das dividas ativas constituem indicadores, no nivel dos elementos constitutivos da riqueza pessoal, das transformações processadas nos cinqüenta últimos anos do século passado, e portanto ligadas à expansão da economia cafeeira em São Paulo" (Mello, 1985:99). Para o vale do Paraíba paulista, ver Marcondes (1998:236-53).
} 
Catão, Luis A. V. A new wholesale price index for Brazil during the period 1870-1913. Revista Brasileira de Economia. Rio de Janeiro, FGV, 46(4):51933, out./dez. 1992.

Dean, Warren. Rio Claro: um sistema brasileiro de grande lavoura, 18201920. Rio de Janeiro, Paz e Terra, 1997.

Faria, Sheila Siqueira de Castro. A colônia em movimento: fortuna e família no cotidiano colonial (Sudeste, século XVIII). Niterói, ICHF/UFF, 1994. (Tese de Doutorado.)

Ferreira, Marieta de Moraes. A crise dos comissários de café do Rio de Janeiro. Niterói, ICHF/UFF, 1977. (Tese de Mestrado.)

Hanley, Anne Gerard. Capital markets in the coffee economy: financial institutions and economic change in São Paulo, Brazil, 1850-1905. Stanford University, 1995. (Tese de Doutorado.)

Lamoreaux, Naomi R. Banks, kinship, and econonomic development: the New England case. Journal of Economic History, 46(3):647-67, Sept. 1986.

Marcondes, Renato Leite. A arte de acumular na economia cafeeira: vale do Paraíba, século XIX. Lorena, Stiliano, 1998.

- Um "capitalista" do século XIX: Joaquim José Moreira Lima (1807-1879). Congresso Internacional da Brasa, 5. Anais, Recife, 2000.

Mello, Pedro Carvalho de. A economia da escravidão nas fazendas de café: 1850-1888. Rio de Janeiro, PNPE, 1984.

Mello, Zélia Cardoso de. A metamorfose da riqueza: São Paulo, 1845-1895. São Paulo, Hucitec/Prefeitura do Município de São Paulo/Secretaria Municipal da Cultura, 1985.

Peláez, Carlos Manuel \& Suzigan, Wilson. História monetária do Brasil: análise da política, comportamento e instituições monetárias. 2 ed. Brasília, Ed. da Universidade de Brasília, 1981.

Saes, Flávio Azevedo Marques de. Crédito e bancos no desenvolvimento da economia paulista (1850-1930). São Paulo, IPE/USP, 1986.

Schulz, John. A crise financeira da Abolição: 1875-1901. São Paulo, Edusp/Instituto Fernand Braudel, 1996. 
Slenes, Robert W. Grandeza ou decadência? O mercado de escravos e a economia cafeeira da província do Rio de Janeiro (1850-1888). In: Costa, Iraci del Nero da. Brasil: história econômica e demográfica. São Paulo, IPEUSP, 1986. p. 103-56.

Smith, George David \& Sylla, Richard. The transformation of financial capitalism: an essay on the history of american capital markets. Financial Markets, Institutions and Instruments, 2(2):1-61, 1993.

Sweigart, Joseph Earl. Financing and marketing Brazilian export agriculture: the coffee factors of Rio de Janeiro, 1850-1888. University of Texas, 1980. (Tese de Doutorado.)

Taunay, Afonso de Escragnolle. História do café no Brasil. Rio de Janeiro, Departamento Nacional do Café (DNC), 1939. 15 v. 